\title{
Prevalence and factors associated with incomplete immunization of children (12-23 months) in Kwabre East District, Ashanti Region, Ghana
}

Anthony Wemakor ${ }^{1 *} \mathbb{D}$, Gideon Kofi Helegbe ${ }^{2}$, Alhassan Abdul-Mumin ${ }^{3}$, Shadrack Amedoe ${ }^{1}$, Jessica Adjoa Zoku ${ }^{1}$ and Ahimah Ivy Dufie ${ }^{1}$

\begin{abstract}
Background: Childhood immunization is one of the most cost effective health interventions but its rate has been declining recently in Ghana. Information on immunization coverage and determinants is needed to improve immunization programmes. The objective of this study was to determine the prevalence and factors associated with incomplete immunization of children (12-23 months) in Kwabre East District, Ghana.

Methods: A cross-sectional, community-based survey involving 322 children and their mothers was carried out. Data were collected on socio-demographic characteristics of mothers, childhood immunization history and mothers' knowledge and practices of immunization using a structured questionnaire. Children were classified as incompletely immunized if they failed to receive at least one of 8 vaccine doses: - one dose of Bacillus Calmette-Guérin (BCG), 3 doses each of pentavalent, 3 doses of polio and one dose of measles per WHO/UNICEF definition. Chi-square and logistic regression analyses were used to identify the factors associated with incomplete immunisation.
\end{abstract}

Results: The prevalence of incomplete immunization was low (15.5\%) suggesting high immunisation coverage but the coverage of the second measles dose, taken at 18 months of age, was the lowest (23.9\%). Most of the mothers knew the importance of immunisation (95.7\%) and at least one vaccine-preventable disease or symptom (84.9\%). Two factors associated with incomplete immunisation in bivariate analyses (community of residence, and mother's knowledge of number of oral polio vaccines given to children) were no longer significant in a logistic regression model. Compared to children in Aboaso, children in Gyamfi Wonoo ( $A O R=1.81,95 \% \mathrm{Cl}=0.80-4.08$ ), Mamponteng (Bonwunu) ( $\mathrm{AOR}=0.59$, $95 \% \mathrm{Cl}=0.24-1.48)$ and Mamponteng (Town) ( $\mathrm{AOR}=0.63,95 \% \mathrm{Cl}=0.26-1.55)$ had similar odds of incomplete immunisation. Similarly, mother's lack of knowledge of the number of doses of polio vaccine given to children had no effect on the odds of incomplete immunisation ( $A O R=0.53,95 \% \mathrm{Cl}=0.22-1.26)$.

Conclusions: Immunization coverage is high in the Kwabre East district but very few children received the second measles dose. None of the maternal and child factors assessed is associated with immunisation coverage. Further research is needed to identify the determinants of immunisation coverage and the reasons for the low uptake of second measles dose in the study area.

Keywords: Immunisation coverage, Determinants of immunisation, Children, Ashanti Region, Ghana

\footnotetext{
* Correspondence: anthonywemakor@yahoo.com

'Department of Nutritional Sciences, School of Allied Health Sciences,

University for Development Studies, Tamale, Ghana

Full list of author information is available at the end of the article
}

(c) The Author(s). 2018 Open Access This article is distributed under the terms of the Creative Commons Attribution 4.0 International License (http://creativecommons.org/licenses/by/4.0/), which permits unrestricted use, distribution, and reproduction in any medium, provided you give appropriate credit to the original author(s) and the source, provide a link to the Creative Commons license, and indicate if changes were made. The Creative Commons Public Domain Dedication waiver (http://creativecommons.org/publicdomain/zero/1.0/) applies to the data made available in this article, unless otherwise stated. 


\section{Background}

Childhood immunization is one of the most cost-effective interventions in health care delivery [1]. In Ghana, the immunization schedule normally requires children to receive 16 vaccine doses from birth up to the age of 23 months [2] but in 2016, a new vaccination was added for protection against meningitis. Children therefore receive a dose of Bacille CalmetteGuerin (BCG) at birth; 4 doses of Oral Polio Vaccine (OPV) at birth, and at 6, 10 and 14 weeks of age; 3 doses of Diphtheria, Pertusis, Tetanus, Haemophilus influenzae type B and Hepatitis B (DPT/HiB/HepB) pentavalent vaccine at 6,10 and 14 weeks of age, 3 doses of pneumococcal vaccine at 6,10 and 14 weeks of age, and 2 doses of rotavirus vaccine at 6 and 10 weeks of age. Thereafter, they receive a dose each of yellow fever and combined measles/rubella vaccines at 9 months of age and a dose each of measles-only and meningitis $\mathrm{A}$ vaccines at 18 months of age.

Immunisation coverage is useful for monitoring the effectiveness of immunisation programmes [3]. In Ghana, the coverage of childhood immunisation had reduced nationally (and also by region) from 79 to $77 \%$ with Western Region recording the most reduction from 82 to $69 \%$ from 2008 to 2014 [2]. Within the same period the percentage of children that received none of the childhood immunisations increased from 1 to $2 \%$ nationally. In the Ashanti region, immunisation coverage reduced from $85 \%$ in 2008 to $79 \%$ in 2014 [2]. Monitoring immunisation coverage and determinants at sub-national levels is essential for prioritizing and tailoring immunisation campaigns and operational plans to address immunization gaps and reach every child with life-saving vaccines. The objective of this study was to determine the prevalence and factors associated with incomplete immunization of children (12-23 months) in Kwabre East District, Ashanti Region, Ghana.

\section{Methods}

A community-based cross-sectional study involving children aged 12-23 months and their mothers/caregivers was conducted in four communities of Mamponteng (Bonwunu), Mamponteng (Town), Gyamfi Wonoo, and Aboaso in four sub-districts in Kwabre East District, Ashanti Region, Ghana. The study period covered January and February, 2017.

\section{Sample size determination and sampling}

The minimum required sample size was determined using the single population formula by Snedecor and Cochran $\mathrm{n}=(\mathrm{t})^{2 *}(\mathrm{p})(\mathrm{q}) /(\mathrm{d})^{2}$, where $\mathrm{n}=$ sample size, $\mathrm{t}=$ reliability coefficient associated with a selected confidence level, $\mathrm{p}=$ estimated proportion of an event of interest, $\mathrm{q}=$ $\mathrm{p}-1$, and $\mathrm{d}=$ desired margin of error. Using the population size of children aged 11-23 months in the four study communities $(n=792)$, the coverage of complete immunization in children 11-23 months in the Ashanti Region of $79.0 \%$ [2], the reliability coefficient associated with $95 \%$ confidence level of 1.96 , and the margin of error of $5 \%$ a minimum sample size of 192 was estimated. This was multiplied by 1.5 to account for cluster sampling and increased by $10 \%$ to obtain the final sample size of 322 . The four communities were randomly sampled from four sub-districts and the number of children sampled from each sub-district was proportional to the total number of children 11-23 months in that sub-district. The number of children sampled in the four communities were 65,89 , 79 and 89 for Gyamfi Wonoo, Mamponteng (Town), Aboaso, and Mamponteng (Bonwunu) respectively.

Mother-child pairs were selected using systematic random sampling. The sampling interval for each community was obtained by dividing the total number of children in that community by the number of sample required from that community. The starting point was selected randomly from the sampling interval and the sampling interval was added until the required number of children was obtained from the community.

Data were collected using a structured questionnaire on socio-demographic factors of mothers and children, immunization history of children and mother's knowledge and practices of immunization. An immunisation card served as the main source of immunisation history of the child. The questionnaire consisted of both close and open-ended questions prepared based on literature review of previous work done on the subject. The questionnaire written in English was translated into Akan and back-translated into English independently by two persons very proficient in both the English and Akan languages to ensure the accuracy of the translation. Misunderstandings and unclear wordings identified in each case were corrected. The questionnaire was then pre-tested with 50 motherchild pairs in another community with similar characteristics as the study communities and fine-tuned further where necessary. The questionnaire was administered in Akan, the local language spoken in the study area, by three final year students of the Department of Nutritional Sciences, University for Development Studies, Tamale, who speak both English and Akan fluently. These students were trained in questionnaire administration, had excellent understanding of the questionnaire, and participated in the pre-testing of the questionnaire. A supervisor sampled and interviewed some of the interviewees and had comparably the same findings as the enumerators during the pre-testing. 


\section{Study variables \\ Incomplete immunisation}

According to the World Health Organisation/UNICEF Guidelines, complete immunization is defined as receipt of one dose of BCG, 3 doses of pentavalent, 3 doses of polio and one dose of measles within the first year of life [4]. Based on this definition any child who did not receive all these 8 vaccine doses before 12 months of age was classified as incompletely immunized. This is the dependent variable of the study.

\section{Household socio-economic status}

To assess socio-economic status of households, information was collected on the availability in the households of 14 items: mobile phone, TV set, satellite dish, sewing machine, mattress, radio, DVD player, bicycle, motorcycle, refrigerator, personal computer, electric fan, animal drawn cart, and car. Each household item was scored " 1 " if present in the household otherwise "0". Using principal component analysis, a wealth score was derived for each household and the scores were grouped and divided into tertiles: low, medium and high tertiles (See Additional file 1).

\section{Maternal knowledge on immunisation score}

To summarize mothers' knowledge on immunisation, the responses to 6 of the immunisation knowledge questions (i.e., importance of immunisation) were coded and scored. For each of the questions, a correct response was awarded a score of " 1 " and an incorrect response a score of " 0 " and all the scores were summed up to give the summary score. The summary score was then divided at midpoint into 2 categories i.e., "low" (0-3 scores) and "high" (4-6 scores).

\section{Data analysis}

Data were analyzed using Stata (version 13). The association between maternal and child factors and child immunization status was explored using Chi-square test and logistic regression analysis. Factors that were statistically significant in bivariate analyses with Chi-square were entered into a logistic regression model in order to identify the independent determinants of incomplete immunization. In all analyses, a $p$-value less than 0.05 was considered statistically significant.

\section{Ethical considerations}

Ethics permission for the study was granted by the Ethics Committee of the School of Medicine and Health Sciences/School of Allied Health Sciences, University for Development Studies, Tamale, Ghana. Informed consent was obtained from study participants before interviews were conducted. It was made clear to the study participants that they had the right to withdraw their participation at any time during data collection and that the information being collected will be kept confidential, accessed only by members of the research team and used only for the purposes of this research.

\section{Results \\ Socio-demographic characteristics of mothers and children}

A total of 322 mothers and their children were surveyed. The ages of the mothers ranged from 17 to 55 years with a mean of 29.9 (95\% confidence interval $=29.3-30.5$ ) years and most (34.2\%) were in the age range $30-34$ years (Table 1). The study subjects consisted predominantly of Christians (82.6\%) and married mothers (83.5\%) and most (35.7\%) were of low household wealth tertile. About halve of the children were males (51.2\%) and in the age range $12-15$ months (45.0\%).

\section{Immunisation coverage}

Children are required to receive seven vaccine-specific immunisations in six rounds from birth up to 23 months. Immunisation rates for four vaccine-specific immunizations (polio, pentavalent, rotavirus and pneumonia) were at least $90.0 \%$ (range $90.1-96.9 \%$ ) but the rate was about a fifth $(23.9 \%)$ for measles-only vaccine taken at 18 months of age.

The coverage of immunisation increased from $94.7 \%$ at first round (at birth) to about $97.0 \%$ in rounds 2 (at 6 weeks), 3 (at 10 weeks) and 4 (at 14 weeks) then decreased to $93.5 \%$ in round 5 (at 9 months). The coverage of individual vaccine doses was highest (97.8\%) for polio 1 , pentavalent 1 , pneumococcal 1 and rotavirus 1 followed by polio 3 , pentavalent 3 and pneumococcal 3 (96.9\%). The measles only vaccine taken at round 6 (18 months) had the lowest prevalence $23.9 \%$ (Table 2). Of all the children, $272(84.5 \%)$ were fully immunized (i.e. received one dose of BCG, 3 doses each of pentavalent and polio and one dose of measles within first year of life), 50 (15.5\%) were partially immunized, and none of the children failed to receive a single vaccine.

\section{Mothers' knowledge and practices of immunization}

A greater majority of the mothers (more than 90\%) knew the importance of childhood immunisations (i.e., vaccines protect, build immunity, prevent infections, ensures good health), and symptoms of vaccine preventable diseases with $86.3 \%$ able to mention at least one vaccine preventable disease (Table 3). A little over two-thirds (70\%) of the mothers knew when children were supposed to complete their immunisations but knowledge on the age at which children receive measles/rubella immunisation (33.2\%) and the number of doses of oral polio vaccine (9.9\%) was low. Using a summary score for immunisation knowledge, 
Table 1 Socio-demographic factors of parents and children

\begin{tabular}{lll}
\hline Socio-demo graphic characteristic & Frequency $(\mathrm{N})$ & Percent \\
\hline $\begin{array}{lll}\text { Age group of mother (years) } \\
\quad 25\end{array}$ & 55 & \\
$25-29$ & 102 & 17.1 \\
$30-34$ & 110 & 31.7 \\
$>34$ & 55 & 34.2 \\
Total & 322 & 17.1
\end{tabular}

Religion

Christian

Marital status

Single

Married

Widowed

Total

Ethnicity

Akan

Others

Total

Occupation

Trading

Office work

Health work

Teaching

Housewife

Others

Total

Mother's educational level

No education

Primary

Middle/ JHS

SHS/ Vocational

Tertiary

Total

Number of household members

$1-4$

$>4$

Total

Household wealth index (tertile)

Low

Medium

High

Total

109

98

322

No. of children less than 5 years in the household

55.6

3.1

1.9

6.8

16.1

16.5

100.0
Table 1 Socio-demographic factors of parents and children (Continued)

\begin{tabular}{lll}
\hline Socio-demo graphic characteristic & Frequency $(\mathrm{N})$ & Percent \\
\hline 1 & 197 & 61.2 \\
2 & 117 & 36.3 \\
$3+$ & 8 & 2.5 \\
Total & 322 & 100.0 \\
Community of residence & & \\
Gyamfi Wonoo & 65 & 20.2 \\
Mamponteng (Town) & 89 & 27.6 \\
Aboaso & 79 & 24.5 \\
Mamponteng (Bonwunu) & 89 & 27.6 \\
Total & 322 & 100.0 \\
Age group of child (months) & & \\
12-15 & 145 & 45.0 \\
16-19 & 115 & 35.7 \\
20-23 & 62 & 19.3 \\
Total & 322 & 100.0 \\
Sex of child & & \\
Male & 165 & 51.2 \\
Female & 157 & 100.0 \\
Total & 322 & \\
\hline
\end{tabular}

a high percentage of the mothers had knowledge on childhood immunization (66.5\%). Majority of respondents indicated that health workers never used unpleasant words on them (66.5\%), always communicated the next date of immunisation to them (72.0\%), and most said they always explained the significance of childhood immunization (41.3\%). On the practice of immunisation, $61.8 \%$ and $17.1 \%$ of mothers said their children ever experienced fever and abscess at injection site respectively.

\section{Factors associated with incomplete immunization}

Bivariate analyses using Chi-square were performed to identify child-, mother- or household-related factors associated with immunization status of children. In these analyses the community of residence $\left(\chi^{2}{ }_{(3)}=10.624, p=0.014\right)$ and mother's knowledge of number of oral polio vaccine doses $\left(X^{2}{ }_{(1)}=4.298, p=0.038\right)$ were found to be associated with immunization status (Tables 4 and 5), whiles mother's marital status showed borderline significance $\left(\chi^{2}{ }_{(1)}=\right.$ 3.9181, $p=0.048)$. No associations were obtained for child characteristics (sex and age), or other maternal and household characteristics evaluated.

In multivariate analysis, factors significant in bivariate analyses with incomplete immunization i.e., community of residence and knowledge of oral polio vaccine doses did not remain significant (Table 6). 
Table 2 Coverage of individual vaccine doses

\begin{tabular}{|c|c|}
\hline \multirow[t]{2}{*}{ Immunisation } & Coverage $(N=322)$ \\
\hline & N (\%) \\
\hline \multicolumn{2}{|l|}{ At Birth (Round 1) } \\
\hline BCG & $303(94.1)$ \\
\hline Polio 0 & $295(91.6)$ \\
\hline All & $305(94.7)$ \\
\hline \multicolumn{2}{|c|}{ At 6 Weeks (Round 2) } \\
\hline Polio 1 & $315(97.8)$ \\
\hline Pentavalent 1 & $315(97.8)$ \\
\hline Pneumococcal 1 & $315(97.8)$ \\
\hline Rotavirus 1 & $315(97.8)$ \\
\hline All & $315(97.8)$ \\
\hline \multicolumn{2}{|c|}{ At 10 weeks (Round 3) } \\
\hline Polio 2 & $314(97.5)$ \\
\hline Pentavalent 2 & $314(97.5)$ \\
\hline Pneumococcal 2 & $314(97.5)$ \\
\hline Rotavirus 2 & $314(97.5)$ \\
\hline All & $314(97.5)$ \\
\hline \multicolumn{2}{|c|}{ At 14 Weeks (Round 4) } \\
\hline Polio 3 & $312(96.9)$ \\
\hline Pentavalent 3 & $312(96.9)$ \\
\hline Pneumococcal3 & $312(96.9)$ \\
\hline All & $312(96.9)$ \\
\hline \multicolumn{2}{|c|}{ At 9 Months (Round 5) } \\
\hline Measles/rubella & $298(92.5)$ \\
\hline Yellow fever & $294(91.3)$ \\
\hline All & $309(93.5)$ \\
\hline \multicolumn{2}{|c|}{ At 18 Months (Round 6) } \\
\hline Measles & $77(23.9)$ \\
\hline
\end{tabular}

\section{Discussion}

We estimated the prevalence rate of incomplete immunization of children (12-23 months) and sought to identify its maternal and child-related determinants in Kwabre East, Ghana. Almost a sixth (15.5\%) of the children surveyed were incompletely immunized suggesting high immunization coverage but among antigen-specific immunisations, measles had the least prevalence (23.9\%).

The percentage of children fully immunized in this study population $(84.5 \%)$ is better than both the Ashanti Regional and national coverage rates of $78.9 \%$ and $77.0 \%$ respectively [2] but lower than observed for children in Techiman (89.5\%) [5]. Our rate is slightly higher than the $80.0 \%$ coverage rate recommended for districts by 2020 by the Global Vaccine Action Plan [6]. On the African continent, our rate is comparable to a coverage rate reported for children in Nigeria (84.9\%)
Table 3 Mothers' knowledge and practices of immunization Immunization knowledge $\quad$ Frequency $(\mathrm{N}) \quad$ Percent (\%) and practices

Mother knew the purpose of immunisation

$\begin{array}{lll}\text { Yes } & 308 & 95.7 \\ \text { No } & 14 & 4.3 \\ \text { Total } & 322 & 100.0\end{array}$

Mother mentioned at least one vaccine preventable disease

$\begin{array}{lll}\text { Yes } & 278 & 86.3 \\ \text { No } & 44 & 13.7 \\ \text { Total } & 322 & 100.0\end{array}$

Mother mentioned at least one symptom of vaccine preventable illnesses

$\begin{array}{lll}\text { Yes } & 378 & 86.3 \\ \text { No } & 44 & 13.7 \\ \text { Total } & 322 & 100.0\end{array}$

Mother knew age at which measles/rubella immunisation is given

$\begin{array}{lll}\text { Yes } & 107 & 33.2 \\ \text { No } & 215 & 66.6 \\ \text { Total } & 322 & 100.0\end{array}$

Mother knew the number of doses of oral polio vaccine given to children

$\begin{array}{lll}\text { Yes } & 32 & 9.9 \\ \text { No } & 290 & 90.1 \\ \text { Total } & 322 & 100.0\end{array}$

Mother knew age at which a child is supposed to be fully immunized

$\begin{array}{lll}\text { Yes } & 235 & 73.0 \\ \text { No } & 86 & 27.0 \\ \text { Total } & 322 & 100.0\end{array}$

Knowledge of immunization score

$\begin{array}{lll}\text { Low }(0-3) & 108 & 33.5 \\ \text { High (4-6) } & 214 & 66.5 \\ \text { Total } & 322 & 100.0\end{array}$

Child has ever developed fever following immunization

$\begin{array}{lll}\text { Yes } & 199 & 61.8 \\ \text { No } & 123 & 38.2 \\ \text { Total } & 322 & 100.0\end{array}$

Child has ever developed abscess following immunization

$\begin{array}{lll}\text { Yes } & 55 & 17.1 \\ \text { No } & 267 & 82.9 \\ \text { Total } & 322 & 100.0\end{array}$

Health worker used unpleasant words on mothers during immunization

$\begin{array}{lll}\text { Always } & 14 & 4.3 \\ \text { Sometimes } & 87 & 27.0 \\ \text { Rarely } & 7 & 2.2 \\ \text { Never } & 214 & 66.5 \\ \text { Total } & 322 & 100.0\end{array}$


Table 3 Mothers' knowledge and practices of immunization (Continued)

\begin{tabular}{lcl}
\hline $\begin{array}{l}\text { Immunization knowledge } \\
\text { and practices }\end{array}$ & Frequency $(\mathrm{N})$ & Percent (\%) \\
\hline $\begin{array}{l}\text { Health worker explained the significance of childhood immunisation to } \\
\text { mothers }\end{array}$ & \\
Always & 133 & 41.3 \\
Sometimes & 95 & 29.5 \\
Rarely & 8 & 2.5 \\
Never & 86 & 26.7 \\
Total & 322 & 100.0 \\
Health worker clearly communicated the next date of immunisation \\
to mothers \\
Always & 232 & \\
Sometimes & 27 & 72.0 \\
Rarely & 4 & 8.4 \\
Never & 59 & 1.2 \\
Total & 322 & 18.3 \\
\hline
\end{tabular}

[7] but not for children in Kenya (76.6\%) [8]. Apart from measles, which is taken at ages 9 and 18 months, the coverage of the individual vaccines was equally very high. Immunisation coverage is an important indicator of population health and a measure of the quality of health services provided [9]. The 2014 Ghana Demographic and Health Survey has indicated declining immunization rates [2] and this situation may have alerted individual districts (including study district) to increase their efforts in order to increase coverage. The low prevalence of measles-specific immunisation rate may be attributable to the long period (i.e., 9 months) between the first and second measles doses at rounds five and six respectively. In one study done in India the coverage of measles decreased from 34.9\% (at first dose) to $22.7 \%$ (at second dose) [10].

We assessed mothers' knowledge and practices of immunization. Generally, the mothers' immunisationrelated knowledge is high and most mothers know the importance of immunization for children, vaccine-preventable diseases and their symptoms, and the age at which children are to complete immunisation. This is against the backdrop that about two-thirds of the women had education up to only Junior High School level and it is known that formal education tends to positively influence health knowledge and behaviour [11]. The percentage of mothers who mentioned correctly the age at which children should complete immunization $(73.0 \%)$ was higher than reported for mothers in Nigeria (14.1\%) [12] and in India (52.4\%) [13]. Again, our study recorded a higher percentage of mothers (95.7\%) who knew the benefits of immunisation compared to a study done in India (82.0\%) [14].
Table 4 Association of socio-demographic factors with immunization status of children

\begin{tabular}{|c|c|c|c|c|}
\hline \multirow{2}{*}{$\begin{array}{l}\text { Socio-demographic } \\
\text { factor }\end{array}$} & \multicolumn{3}{|c|}{ Incomplete immunization } & \multirow{2}{*}{$\begin{array}{l}\text { Test } \\
\text { statistics }\end{array}$} \\
\hline & $\overline{\text { No }(\%)}$ & Yes (\%) & Total & \\
\hline \multicolumn{5}{|c|}{ Age group of mother (years) } \\
\hline$<25$ & $44(80.0)$ & $11(20.0)$ & 55 & \multirow{4}{*}{$\begin{array}{l}X^{2}=6.9540 \\
\mathrm{df}=3 \\
P=0.073\end{array}$} \\
\hline $25-29$ & $82(80.4)$ & $20(19.6)$ & 102 & \\
\hline $30-34$ & $101(91.8)$ & $9(8.2)$ & 110 & \\
\hline$>34$ & $45(81.8)$ & $10(18.8)$ & 55 & \\
\hline \multicolumn{5}{|l|}{ Religion of mother } \\
\hline Christian & $225(84.6)$ & $41(15.4)$ & 266 & \multirow{2}{*}{$\begin{array}{l}x^{2}=0.015 \\
\mathrm{df}=1 \\
P=0.902\end{array}$} \\
\hline Non-Christian & $47(83.9)$ & $9(16.1)$ & 56 & \\
\hline \multicolumn{5}{|l|}{ Marital status } \\
\hline Currently married & $232(86.3)$ & $37(13.7)$ & 269 & \multirow{2}{*}{$\begin{array}{l}X^{2}=3.9181 \\
\mathrm{df}=1 \\
P=0.048\end{array}$} \\
\hline Not currently married & $40(75.5)$ & $13(24.5)$ & 53 & \\
\hline \multicolumn{5}{|l|}{ Ethnicity } \\
\hline Akan & $155(85.2)$ & $27(14.8)$ & 182 & \multirow{2}{*}{$\begin{array}{l}X^{2}=0.1532 \\
\mathrm{df}=1 \\
P=0.696\end{array}$} \\
\hline Others & 117 (83.6) & $23(16.4)$ & 140 & \\
\hline \multicolumn{5}{|l|}{ Occupation } \\
\hline Trading & $150(83.8)$ & $29(16.2)$ & 179 & \multirow{2}{*}{$\begin{array}{l}X^{2}=0.1392 \\
\mathrm{df}=1 \\
P=0.709\end{array}$} \\
\hline Others & $122(85.3)$ & $21(14.7)$ & 143 & \\
\hline \multicolumn{5}{|l|}{ Mothers' educational level } \\
\hline None & $19(73.1)$ & $7(26.9)$ & 26 & \multirow{4}{*}{$\begin{array}{l}x^{2}=3.959 \\
\mathrm{df}=4 \\
P=0.412\end{array}$} \\
\hline Primary & $37(80.4)$ & $9(19.6)$ & 46 & \\
\hline Middle/JHS & $129(86.0)$ & $21(14.0)$ & 150 & \\
\hline SHS/vocational school & $57(86.4)$ & $9(13.6)$ & 66 & \\
\hline \multicolumn{5}{|c|}{ Household wealth index (tertile) } \\
\hline Low & $91(79.1)$ & $24(20.9)$ & 115 & \multirow{3}{*}{$\begin{array}{l}X^{2}=3.9055 \\
\mathrm{df}=2 \\
P=0.142\end{array}$} \\
\hline Medium & $95(87.2)$ & $14(12.8)$ & 109 & \\
\hline High & $86(87.8)$ & $12(12.2)$ & 98 & \\
\hline \multicolumn{5}{|l|}{ Community } \\
\hline $\begin{array}{l}\text { Mamponteng } \\
\text { (Bonwunu) }\end{array}$ & $80(89.9)$ & $9(10.1)$ & 89 & \multirow{4}{*}{$\begin{array}{l}X^{2}=10.6245, \\
\mathrm{df}=3, \\
P=0.014\end{array}$} \\
\hline Gyamfi Wonoo & $47(72.3)$ & $18(27.7)$ & 65 & \\
\hline Mamponteng (Town) & 79 (88.8) & $10(11.2)$ & 89 & \\
\hline Aboaso & $66(83.5)$ & $13(16.5)$ & 79 & \\
\hline \multicolumn{5}{|c|}{ Number of household members } \\
\hline$>4$ & $109(81.3)$ & $25(18.7)$ & 134 & \multirow{2}{*}{$\begin{array}{l}x^{2}=1.7129 \\
\mathrm{df}=1 \\
P=0.191\end{array}$} \\
\hline$<=4$ & $163(86.7)$ & $25(13.3)$ & 188 & \\
\hline \multicolumn{5}{|c|}{ Number of children under five in household } \\
\hline 1 & $169(85.8)$ & $28(14.2)$ & 197 & \multirow{2}{*}{$\begin{array}{l}x^{2}=0.6688 \\
\mathrm{df}=1 \\
P=0.413\end{array}$} \\
\hline $2+$ & $103(82.4)$ & $22(17.6)$ & 125 & \\
\hline \multicolumn{5}{|c|}{ Age group of child (months) } \\
\hline $12-15$ & $126(86.9)$ & $19(13.1)$ & 145 & $x^{2}=1.4286$ \\
\hline $16-19$ & $96(83.5)$ & $19(16.5)$ & 115 & $\begin{array}{l}\mathrm{df}=2 \\
P=0.490\end{array}$ \\
\hline $20-23$ & $50(80.6)$ & $12(19.4)$ & 62 & \\
\hline Sex of child & & & & \\
\hline Male & $134(81.2)$ & $31(18.8)$ & 165 & $x^{2}=2.74$ \\
\hline Female & $138(87.9)$ & $19(12.1)$ & 157 & $\begin{array}{l}\mathrm{df}=1 \\
P=0.098\end{array}$ \\
\hline
\end{tabular}

Df Degrees of freedom 
Table 5 Association of maternal knowledge and practices of immunization with immunization status of children

\begin{tabular}{|c|c|c|c|c|}
\hline \multirow[t]{2}{*}{$\begin{array}{l}\text { Immunization } \\
\text { knowledge and Practices }\end{array}$} & \multicolumn{3}{|c|}{$\begin{array}{l}\text { Incomplete } \\
\text { Immunisation }\end{array}$} & \multirow[t]{2}{*}{$\begin{array}{l}\text { Test } \\
\text { statistics }\end{array}$} \\
\hline & No (\%) & Yes (\%) & Total & \\
\hline
\end{tabular}

Mother mentioned at least one vaccine preventable disease

$\begin{array}{lllll}\text { Yes } & 236(84.9) & 42(15.1) & 278 & \begin{array}{l}X^{2}=0.2736, \\ \text { No }\end{array} \\ 36(81.8) & 8(18.2) & 44 & \begin{array}{l}\mathrm{df}=1, \\ P=0.601\end{array}\end{array}$

Mother mentioned at least one symptom of vaccine preventable illnesses

\begin{tabular}{|c|c|c|c|}
\hline Yes & 237 (85.3) & $41(14.7)$ & 278 \\
\hline No & $35(79.6)$ & $9(20.4)$ & 44 \\
\hline
\end{tabular}

Mother knew age at which measles/rubella immunisation is given

$\begin{array}{lllll}\text { Yes } & 95(88.8) & 12(11.2) & 107 & \begin{array}{l}X^{2}=2.2726, \\ \text { No }\end{array} 117(82.3) \\ 38(17.7) & 215 & \begin{array}{l}\mathrm{df}=1, \\ P=0.132\end{array}\end{array}$

Mother knew number of doses of oral polio vaccine given to children

$\begin{array}{lllll}\text { Yes } & 23(71.9) & 9(28.1) & 32 & \begin{array}{l}x^{2}=4.2985, \\ \mathrm{df}=1,\end{array} \\ \text { No } & 249(85.9) & 41(14.1) & 290 & P=0.038\end{array}$

Mother knew age at which a child is supposed to be fully immunized

$\begin{array}{lllll}\text { Yes } & 204(86.6) & 31(13.2) & 235 & X^{2}=3.619, \\ \text { No } & 68(78.2) & 19(21.8 & 87 & \begin{array}{l}\mathrm{df}=1, \\ \end{array}=0.057\end{array}$

Knowledge of immunization score

$\begin{array}{lllll}\text { Low (0-3) } & 88(81.5) & 20(18.5) & 108 & \begin{array}{l}X^{2}=1.1080, \\ \mathrm{df}=1, \\ \text { High (4-6) }\end{array} 184(86.0) \\ 30(14.0) & 214 & \begin{array}{l}P=0.293\end{array}\end{array}$

Mother have fears that vaccines can harm children

$\begin{array}{lllll}\text { Yes } & 47(83.9) & 9(16.1) & 56 & \begin{array}{l}x^{2}=0.0153, \\ \mathrm{df}=1,\end{array} \\ \text { No } & 225(84.6) & 41(15.4) & 266 & \mathrm{P}=0.902\end{array}$

Child has ever developed fever after immunisation

$\begin{array}{lllll}\text { Yes } & 173(86.9) & 26(13.1) & 199 & \begin{array}{l}X^{2}=2.4086, \\ \mathrm{df}=1,\end{array} \\ \text { No } & 99(80.5) & 24(19.5) & 123 & \begin{array}{l}P=0.121\end{array}\end{array}$

Child has ever developed abscess after immunization

\begin{tabular}{|c|c|c|c|}
\hline Yes & $45(81.8)$ & $10(18.2)$ & 55 \\
\hline No & $227(85.0)$ & $40(15.0)$ & 267 \\
\hline
\end{tabular}

Health worker used unpleasant words on mothers during immunization

$\begin{array}{lllll}\text { Always/sometimes } & 83(82.2) & 18(17.8) & 101 & \begin{array}{l}X^{2}=0.5903, \\ \mathrm{df}=1, \\ \text { Rarely/never }\end{array} \\ & 189(85.5) & 32(14.5) & 221 & \begin{array}{l}P=0.442\end{array}\end{array}$

Health worker explained the significance of childhood immunisations to mothers

$\begin{array}{lllll}\text { Always/sometimes } & 197(86.4) & 31(13.6) & 228 & X^{2}=2.221, \\ \text { Rarely/never } & 75(79.8) & 19(20.2) & 94 & \begin{array}{l}\mathrm{df}=1, \\ P=0.136\end{array}\end{array}$

Health worker clearly communicated the next date for immunisation to mothers

\begin{tabular}{lllll} 
Always/sometimes & $222(85.7)$ & $37(14.3)$ & 259 & $x^{2}=1.557$, \\
Rarely/never & $50(79.4)$ & $13(20.6)$ & 63 & $\begin{array}{l}\mathrm{df}=1, \\
P=0.212\end{array}$ \\
\hline
\end{tabular}

Df Degrees of freedom
Table 6 Multivariate analysis of factors associated with incomplete immunization in bivariate analyses

\begin{tabular}{llll}
\hline Variable & $\begin{array}{l}\text { Adjusted Odds } \\
\text { Ratio }\end{array}$ & $\begin{array}{l}\text { 95\% Confidence } \\
\text { Interval }\end{array}$ & P-value \\
\hline $\begin{array}{l}\text { Community of residence } \\
\text { Aboaso }\end{array}$ & 1.00 & & \\
Gyamfi Wonoo & 1.81 & $0.80-4.08$ & 0.156 \\
Mamponteng (Bonwunu) & 0.59 & $0.24-1.48$ & 0.266 \\
Mamponteng (Town) & 0.63 & $0.26-1.55$ & 0.317
\end{tabular}

Mothers knew the number of doses of oral polio vaccine given to children

\begin{tabular}{llll} 
Yes & 1.00 & & \\
No & 0.53 & $0.22-1.26$ & 0.148 \\
\hline
\end{tabular}

Overall, knowledge on immunization is high and the proportion of mothers $(66.5 \%)$ with this knowledge can be compared to the $70.0 \%$ of mothers reported to be knowledgeable on immunization in Nigeria [15]. The mothers also have positive attitude towards the health workers reporting that they did not use unpleasant words on them. The observations in this study area suggest a combination of maternal interest in child health, availability of child preventive health services and friendly health workers in the District.

The study evaluated a range of maternal and child socio-demographic characteristics and maternal immunisation-related knowledge and practices as they have been shown to predict immunisation coverage [5, 16-19]. Among the factors evaluated, the community of residence and mothers' knowledge of the number of doses of polio vaccines were significant only in bivariate analysis. Although we found a higher prevalence of incompletely immunized children belonging to unmarried mothers compared to married mothers (24.5\% versus $13.7 \%)$, this did not reach statistical significance $(p=0.048)$ in bivariate analysis. Overall, we failed to find a link between maternal/child socio-demographic characteristics, household factors or immunization-related knowledge of mothers and children's immunization status. This may reflect a lack of association between these factors and child immunisation status in the study area or the lack of sufficient power by the study to identify child immunisation determinants.

Our study has some limitations that should be considered in interpreting its findings. The use of a cross-sectional study design in which both the immunisation coverage and determinants were assessed at the same time meant that a cause-effect relationship cannot be established. We employed cluster sampling but did not take that into consideration in the analysis. Consequently, we computed $95 \%$ confidence intervals for means instead of standard deviations. Our sample size may have been inadequate to identify the determinants 
of immunisation, if there were, for our study population. Given the high immunisation coverage in the District, children who were not completely vaccinated may have been underrepresented and this may have underpowered the study. Despite these limitations we believe our study provides some insights into the coverage and determinants of childhood immunisation in the Kwabre East District and the findings may be relevant and generalizable to communities in the District with similar characteristics as the study communities.

\section{Conclusions}

In exception of the second dose of measles vaccine taken at 18 months of age, the coverage of childhood immunisation in the Kwabre East District is high. However, our study did not find any association between maternal and child socio-demographic characteristics, household factors or immunisation-related knowledge of mothers and coverage of childhood immunisation. Mothers generally have high level of knowledge on childhood immunization. Further studies are required to identify the determinants of incomplete immunisation and to understand the low uptake of the second measles dose in the study area. Education campaigns should focus on the importance of the measles vaccine to improve the uptake of its second dose.

\section{Additional file}

Additional file 1: Principal component analysis of household items to create a household wealth index. This is a Stata output on the use of principal component analysis to create a household wealth index. (TXT 6 kb)

\section{Abbreviations}

BCG: Bacillus Calmette-Guérin; OPV: Oral Polio Vaccine

\section{Acknowledgements}

We thank the parents who participated in the study.

\section{Funding}

The study was funded by the authors.

\section{Availability of data and materials}

The minimal dataset analysed during the current study are available from the corresponding author on reasonable request.

\section{Authors' contributions}

AW conceived and designed the study. Data were collected by SA, JAZ and AID under the supervision of GKH and AAM. The collected data were analysed by AW. GKH and AAM drafted the manuscript and AW contributed to it. All authors read and approved the final manuscript.

\section{Authors' information}

AW holds a PhD and is a Lecturer in the School of Allied Health Sciences, University for Development Studies (UDS), Ghana. GKH holds a PhD and is a Senior Lecturer in the School of Medicine and Health Sciences, UDS, Ghana. AAM is a Fellow of Ghana College of Physicians and a Senior Lecturer in the School of Medicine and Health Sciences, UDS, Ghana. SA, JAZ and AID hold BSc degrees.

\section{Ethics approval and consent to participate}

The study was approved by the Institutional Review Board of School of Allied Health Sciences/School of Medicine and Health Sciences, University for Development Studies, Tamale, Ghana. The study participants were also informed about the objectives of the study, privacy and data protection and gave informed consent prior to being enrolled into the study.

\section{Consent for publication}

Not applicable.

\section{Competing interests}

The authors declare that they have no competing interests.

\section{Publisher's Note}

Springer Nature remains neutral with regard to jurisdictional claims in published maps and institutional affiliations.

\section{Author details}

'Department of Nutritional Sciences, School of Allied Health Sciences, University for Development Studies, Tamale, Ghana. ${ }^{2}$ Department of Biochemistry and Molecular Medicine, School of Medicine and Health Sciences, University for Development Studies, Tamale, Ghana. ${ }^{3}$ Department of Paediatrics and Child Health, Tamale Teaching Hospital/School of Medicine and Health Sciences, University for Development Studies, Tamale, Ghana.

Received: 22 February 2018 Accepted: 27 September 2018

Published online: 19 November 2018

References

1. Miller M, Hinman A. Economic analyses of vaccine policies, vaccines. Philadelphia: Elsevier Inc; 2004.

2. GSS, GHS, ICF International. Ghana Demographic and Health Survey 2014. Rockville, Maryland, USA; 2015.

3. Prinja S, Gupta M, Singh A, Kumar R. Effectiveness of planning and management interventions for improving age-appropriate immunization in rural India. Bull World Health Organ. 2010;88(2):97-103.

4. Etana B, Deressa W. Factors associated with complete immunization coverage in children aged 12-23 months in ambo Woreda, Central Ethiopia. BMC Public Health. 2012;12(1):566.

5. Adokiya MN, Baguune B, Ndago JA. Evaluation of immunization coverage and its associated factors among children 12-23 months of age in Techiman municipality, Ghana, 2016. Arch Public Health. 2017;75(1):28

6. World Health Organization. Global Vaccine Action Plan 2011-2020. 2013.

7. Tagbo BN, Eke CB, Omotowo BI, Onwuasigwe CN, Onyeka EB, Mildred UO Vaccination coverage and its determinants in children aged 11-23 months in an urban district of Nigeria. World J Vaccines. 2014;4(04):175.

8. Maina LC, Karanja S, Kombich J. Immunization coverage and its determinants among children aged 12-23 months in a peri-urban area of Kenya. Pan Afr Med J. 2013;14(1):3.

9. Oliveira MFS, Martinez EZ, JSY R. Factors associated with vaccination coverage in children < 5 years in Angola. Revista de saude publica. 2014;48(6):906-15.

10. Siddiqui S, Akbar M, Mehtab A, Zafar M, Shahid S, Ahmed S, Aziz S. Frequency of immunisation of children upto five years of age according to vaccination card in Karachi-A multicentre study. Ann Abbasi Shaheed Hosp Karachi Med Dent Coll. 2017;22(1):12-19.

11. Hahn RA, Truman BI. Education improves public health and promotes health equity. Int J Health Serv. 2015:45(4):657-78.

12. Abdulraheem I, Onajole A, Jimoh A, Oladipo A. Reasons for incomplete vaccination and factors for missed opportunities among rural Nigerian children. J Public Health and Epidemiol. 2011;3(4):194-203.

13. Birhanu S, Anteneh A, Kibie Y, Jejaw A. Knowledge, attitude and practice of mothers towards immunization of infants in health Centres at Addis Ababa, Ethiopia. Am J Health Res. 2016:4(1):6-17.

14. Marskole P, Rawat R, Chouhan P, Sahu P, Choudhary R. Knowledge, attitude, and practices on vaccination among mothers of under-5 children, attending immunization out patients Department at Gwalior, Madhya Pradesh. Int J Scientific Study. 2016;3(12):231-3

15. Ubajaka F, Ukegbu A, Okafor N, Ejiofor O. The prevalence of missed opportunities for immunization among children utilizing immunization services in Nnamdi Azikiwe University Teaching Hospital, Nnewi. J Biol Agric Healthc. 2012;6(2):112-19. 
16. Dwumoh D, Essuman EE, Afagbedzi SK. Determinant of factors associated with child health outcomes and service utilization in Ghana: multiple indicator cluster survey conducted in 2011. Arch Public Health. 2014;72(1):42.

17. Animaw W, Taye W, Merdekios B, Tilahun M, Ayele G. Expanded program of immunization coverage and associated factors among children age 12-23 months in Arba Minch town and Zuria District, southern Ethiopia, 2013. BMC Public Health. 2014;14(1):464

18. Odusanya OO, Alufohai EF, Meurice FP, Ahonkhai VI. Determinants of vaccination coverage in rural Nigeria. BMC Public Health. 2008;8(1):381

19. Baguune B, Ndago JA, Adokiya MN. Immunization dropout rate and data quality among children 12-23 months of age in Ghana. Arch Public Health. 2017;75(1):18.

Ready to submit your research? Choose BMC and benefit from:

- fast, convenient online submission

- thorough peer review by experienced researchers in your field

- rapid publication on acceptance

- support for research data, including large and complex data types

- gold Open Access which fosters wider collaboration and increased citations

- maximum visibility for your research: over $100 \mathrm{M}$ website views per year

At BMC, research is always in progress.

Learn more biomedcentral.com/submissions 